\title{
CARACTERÍSTICAS AGRONÔMICA DE HÍBRIDOS DIPLOIDES DE BANANEIRA EM TRÊS CICLOS DE PRODUÇÃO EM CRUZ DAS ALMAS, BAHIA ${ }^{1}$
}

\author{
LAURO SARAIVA LESSA², CARLOS ALBERTO DA SILVA LEDO, \\ SEBASTIÃO DE OLIVEIRA E SILVA ${ }^{3}$, EDSON PERITO AMORIM ${ }^{3}$, \\ TADÁRIO KAMEL DE OLIVEIRA ${ }^{2}$
}

RESUMO - O objetivo deste trabalho foi avaliar agronomicamente híbridos diploides de bananeira, em três ciclos de produção, visando à seleção de genótipos para utilização em programas de melhoramento. O experimento foi conduzido entre os anos de 2005 e 2007, em blocos casualizados, no esquema de parcela subdividida no tempo, com quatro repetições, em Cruz das Almas, Bahia. Os híbridos diploides 4279-06, TH03-01, 8987-01, 0323-03, 1318-01, 0116-01, 8694-20, 1304-06 e 9179-03 foram avaliados quanto à altura de plantas, diâmetro do pseudocaule, número de folhas vivas na floração e na colheita, presença de pólen, período de formação do cacho, número de pencas e frutos, e massa média dos frutos. O híbrido 1304-06 apresentou a maior altura nos três ciclos estudados, enquanto o 0323-03 e o 1318-01 apresentaram porte intermediário. À exceção des 8987-01, 0323-03, 1304-06 e 9179-03, os demais híbridos apresentaram número de folhas, na floração, superior a oito. Na colheita, 0323-03, 1318-01, 0116-01, 1304-06 e 9179-03 destacaram-se com os maiores números de folhas. Existe variabilidade genética entre os híbridos diploides de bananeira estudados. Os híbridos 4279-06, 0323-03, 1318-01, 0116-01, 1304-06 e 9179-03 apresentaram características agronômicas favoráveis e podem ser utilizados como genitores em programas de melhoramento genético da bananeira.

Termos para indexação: Melhoramento, Musa spp., diploides, variabilidade.

\section{AGRONOMIC TRAITS OF BANANA DIPLOID HYBRIDS IN THREE CYCLE OF PRODUCTION IN CRUZ DAS ALMAS, BAHIA}

\begin{abstract}
The objective of this work was to evaluate agronomic traits of banana diploid hybrids, in three production cycles, seeking the selection of genotypes to use in banana breeding programs. Experiment was conducted between the years 2005 and 2007, in a complete randomized block design in split plot, with four replicates, in Cruz das Almas, Bahia, Brazil. Diploids hybrids 4279-06, TH03-01, 8987-01, 0323-03, 1318-01, 0116-01, 8694-20, 1304-06 and 9179-03, were evaluated regarding to the characters plant height, pseudostem diameter, number of fresh leaves in flowering and harvest, pollen presence, bunch of training period, number of hands and fruits per bunch and fruit average mass. Hybrid 1304-06 showed the greatest height in the three cycles studied, while the 0323-03 and 1318-01 showed intermediary port. Exception of 8987-01, 0323-03, 1304-06 and 9179-03, the other hybrids showed the number of leaves flowering above eight. At harvest, the 0323-03, 1318-01, 0116-01, 1304-06 and 9179-03, highlighted with the largest number of leaves. There is genetic variability among banana diploid hybrid studied. Hybrids 4279-06, 0323-03, 1318-01, 0116-01, 1304-06 and 9179-03, showed favorable agronomic traits and can be used as parents in banana genetic improvement programs.
\end{abstract}

Index terms: Improvement, Musa spp., diploids, variability.

${ }_{1}^{1}$ (Trabalho 028-09) Recebido em: 12-01-2009. Aceito para publicação em: 15-06-2009.

2Embrapa Acre, BR 364, km 14, Caixa Postal 321, CEP 69.914-220, Rio Branco - Acre. E-mails: laurolessa@cpafac.embrapa.br; tadario@cpafac.embrapa.br;

${ }^{3}$ Embrapa Mandioca e Fruticultura Tropical, Rua da Embrapa s/n, Caixa Postal 007, CEP 44.380-000, Cruz das Almas - BA. E-mails: ledo@cnpmf.embrapa.br; ssilva@cnpmf.embrapa.br; edson@cnpmf.embrapa.br. 


\section{INTRODUÇÃO}

A cultura da bananeira assume importância social e econômica em mais de 80 países, principalmente em pequenas propriedades (Silva et al., 2002a). O Brasil é o segundo produtor mundial de bananas, com 7,1 milhões de toneladas em 2007 e uma área cultivada de 519,18 mil hectares (8,05\% de toda área cultivada com lavouras perenes no Brasil), perdendo apenas para a Índia (FAO, 2008; IBGE, 2009).

Mesmo sendo um dos maiores produtores mundiais, as exportações brasileiras são irrisórias quando comparadas com outros países produtores, como o Equador. O baixo volume de exportação está diretamente relacionado com a grande população do País e o elevado consumo per capita e também a falta de técnicas adequadas para o cultivo e a problemas fitossanitários, como doenças e pragas, que podem ocasionar perdas de até $100 \%$ da lavoura (Silva et al., 2002a).

A falta de variedades comerciais de banana que sejam produtivas, com porte adequado, resistentes às principais pragas e doenças, adaptadas a diferentes ecossistemas e aceita por consumidores, constituem-se em fatores limitantes à expansão da cultura (Silva et al., 2000; Donato et al., 2006). Uma das estratégias para suplantar estas limitações é o desenvolvimento de novas cultivares, mediante programas de melhoramento genético. Esses novos genótipos, em sua maioria, são tetraploides, oriundos de cruzamentos entre triploides (variedades comerciais) e diploides melhorados ou selvagens (Silva et al., 2005).

Em bananeira, a variabilidade genética importante para os programas de melhoramento localiza-se nos diploides (Shepherd et al., 1986; Silva et al., 2002b). Portanto, a avaliação agronômica destes pode disponibilizar informações úteis para estimar a variabilidade genética disponível no melhoramento, tanto para a escolha de genitores para cruzamentos entre diploides divergentes, quanto ao cruzamento destes com triploides, para obtenção de novos híbridos tetraploides (Amorim et al., 2008).

Objetivou-se com este trabalho avaliar características agronômicas em híbridos diploides de bananeira (AA), em três ciclos de produção, em Cruz das Almas (BA), visando à seleção de genótipos promissores para serem utilizados em programas de melhoramento da bananeira.

\section{MATERIAL E MÉTODOS}

O experimento foi conduzido no campo experimental da Embrapa Mandioca e Fruticultura Tropical, em Cruz das Almas (BA), entre julho de 2005 e novembro de 2007. O município está situado a $12^{\circ} 40^{\prime} 19^{\prime \prime}$ de latitude sul e $39^{\circ} 06^{\prime} 22^{\prime \prime}$ de longitude oeste a $220 \mathrm{~m}$ de altitude. O clima é tropical quente e úmido, Aw a Am, segundo a classificação de Köeppen, com temperatura média anual de 24,5 C, umidade relativa de $80 \%$ e precipitação média de 1.249,7 mm anuais (Agritempo, 2008).

O solo da área experimental é classificado como um Latossolo Amarelo distrófico, bem drenado, profundo, de textura média e médios teores de argila, apresentando na camada superficial $(0-20 \mathrm{~cm})$ os seguintes atributos químicos: $\mathrm{pH}=5,7 ; \mathrm{P}=$ 4,0 $\mathrm{mg} \mathrm{dm}^{-3} ; \mathrm{K}=0,4 \mathrm{cmol}_{\mathrm{c}} \mathrm{dm}^{-3} ; \mathrm{Ca}=2,4 \mathrm{cmol}_{\mathrm{c}}$

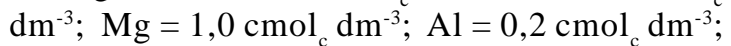
$\mathrm{Na}=0,1 \mathrm{cmol}_{\mathrm{c}} \mathrm{dm}^{-3} ; \mathrm{Al}+\mathrm{H}=2,86 \mathrm{cmol}_{\mathrm{c}}{ }^{\mathrm{c}} \mathrm{dm}^{-3}$; $\mathrm{V}=58 \%$ e $\mathrm{MO}=9,72 \mathrm{~g} \mathrm{dm}^{-3}$.

Os híbridos diploides avaliados foram 4279-06, TH03-01, 8987-01, 0323-03, 1318-01, 0116-01, 8694-20, 1304-06 e 9179-03 (Tabela 1). O material vegetal constituiu-se em mudas tipo 'chifre', com aproximadamente quatro meses de idade, retiradas do Banco Ativo de Germoplasma de Bananeira da Embrapa Mandioca e Fruticultura Tropical. O plantio foi conduzido com irrigação, utilizando-se do sistema de microaspersão, conforme recomendações de Donato et al. (2003) e Coelho et al. (2006). Os tratos culturais foram os recomendados para a cultura da bananeira (Alves \& Oliveira, 1999), e as adubações foram baseadas na análise de solo (Borges et al., 1999).

As características agronômicas avaliadas foram: altura de plantas (m), diâmetro do pseudocaule (cm), número de folhas na floração e na colheita, presença de pólen (por meio da escala de notas: 1 - ausência de pólen; 2 - pequena quantidade de pólen; 3 - média quantidade de pólen; 4 - abundância de pólen), período de formação do cacho (dias), número de pencas, número de frutos e massa média do fruto (g).

O delineamento experimental foi o de blocos casualizados, no esquema de parcela subdividida no tempo, com quatro repetições. Os tratamentos das parcelas foram nove híbridos diploides de bananeira, e das subparcelas, três ciclos de avaliação. Cada parcela foi representada por seis plantas úteis, utilizando o espaçamento de 2,5 m x 2,5 m. Como bordadura, foi utilizada a cultivar Pacovan. Os dados foram submetidos à análise de variância, e a variável número de folhas vivas na colheita foi transformada 
em $\sqrt{\mathrm{x}}$, visando ao atendimento das pressuposições da análise de variância. As médias dos genótipos e dos ciclos foram submetidas aos testes de Scott \& Knott (1974) e Tukey, respectivamente, a 5 \% de probabilidade, utilizando-se do programa SISVAR (Ferreira, 2000). Quando a interação foi significativa, procederam-se os desdobramentos necessários.

\section{RESULTADOS E DISCUSSÃO}

Houve interação significativa para as variáveis: altura de plantas, diâmetro do pseudocaule, número de folhas na floração e na colheita. Para as variáveis: presença de pólen, período de formação do cacho, número de pencas e de frutos, e massa média do fruto, não se observou interação significativa.

O híbrido diploide 1304-06 apresentou a maior altura de planta nos três ciclos de avaliação (primeiro $=2,37 \mathrm{~m}$; segundo $=3,12 \mathrm{~m}$; e terceiro = 3,22 m). No entanto, no terceiro ciclo, além deste, o '0116-01', apresentou, também, a maior altura, diferindo dos demais (Tabela 2). Para este caráter, genótipos de porte baixo são preferíveis, porém estes diploides, uma vez em cruzamento com triploides, podem produzir genótipos com porte adequado na progênie, sendo este um fator que não limita a seleção destes híbridos.

Os híbridos 0323-03, 1318-01 e 0116-01, no primeiro ciclo; '0323-03' e '0116-01', no segundo ciclo; e ‘4279-06’ ‘1318-01' e ‘9179-03’, no terceiro ciclo, formaram um grupo de porte intermediário nos ciclos avaliados. No terceiro ciclo, os híbridos TH03-01, 8987-01, 0323-03 e 8694-20 apresentaram o menor porte. Este caráter, segundo alguns autores (Belalcázar Carvajal, 1991; Alves \& Oliveira, 1999; Silva et al., 2002a; Donato, 2003), é muito importante no melhoramento da cultura, pois influi na densidade de plantio, no manejo e, consequentemente, na produção.

Observou-se, ainda, que o híbrido 8694-20 apresentou a menor altura de planta nos três ciclos (Tabela 2). A baixa estatura deste pode estar relacionada ao seu genitor feminino (0337-02), uma vez que ele apresenta porte baixo (Silva et al., 2001).

Em relação aos ciclos, observou-se que o primeiro apresentou as menores médias para altura de plantas, estando de acordo com os estudos realizados por Silva et al. (2002a), que observaram um incremento na altura de plantas do primeiro para o segundo ciclo de produção em bananeira. Observou-se que todos os híbridos diploides, à exceção do 0323-03, apresentaram estabilidade para este caráter a partir do segundo ciclo.
No diâmetro do pseudocaule, observou-se grande variação entre os ciclos, sendo que o híbrido 4279-06 foi o que apresentou a maior média para os três ciclos. Além deste, os híbridos 0323-03, 869420, 1304-06 e 9179-03, no primeiro ciclo, e '869420’, no segundo, apresentaram as maiores médias, formando um grupo com médias superiores aos demais (Tabela 2). Semelhante à altura de plantas, no primeiro ciclo, foram observadas as menores médias, quando comparado aos demais. Os híbridos 0323-03, 1304-06 e 9179-03 apresentaram estabilidade para o caráter a partir do primeiro ciclo, e os híbridos TH03-01, 1318-01, 0116-01 e 8694-20, no segundo ciclo.

De acordo com Silva et al. (2003), o caráter diâmetro do pseudocaule assume importância no melhoramento genético da bananeira, uma vez que está relacionada ao vigor da planta, além de refletir a capacidade de sustentação do cacho e suscetibilidade ao tombamento.

No primeiro ciclo, os híbridos TH03-01, 8987-01, 1318-01 e 9179-03 obtiveram os maiores números de folhas na floração, formando um grupo com médias superiores aos demais, enquanto no segundo e terceiro ciclos, não se observou diferença estatística entre os híbridos estudados (Tabela 2).

Para Soto Ballestero (1992), o caráter número de folhas na floração é um descritor importante na avaliação de cultivares, uma vez que influencia diretamente no desenvolvimento do cacho. Esta característica também pode indicar o grau de resistência de uma cultivar às sigatokas. Plantas de bananeira tipo Cavendish, necessitam, no mínimo, de oito folhas para a boa formação do cacho. Como pode ser observado na Tabela 2, à exceção dos híbridos 8987-01, 0323-03, 1304-06 e 9179-03, todos os demais genótipos apresentaram número de folhas, na floração, superior a oito.

Quanto ao número de folhas vivas na colheita, observou-se que, no primeiro ciclo, os híbridos 8987-01 e 0323-03 obtiveram as maiores médias e, no segundo ciclo, o '1318-01', '0116-01' e '130406' formaram um grupo distinto dos demais (Tabela 3). Oliveira et al. (2007) afirmaram que o maior ou menor número de folhas na colheita poderia indicar resistência dos genótipos a doenças foliares, como as sigatokas-negra e amarela. Já no terceiro ciclo, não foi verificada diferença entre os genótipos, com médias variando entre 1,00 folha ('TH03-01') e 3,50 folhas ('1318-01').

Lessa (2007), estudando híbridos diploides de bananeira em Cruz das Almas (BA), verificou que os diploides TH03-01, 8694-20, 1304-06 e 9179-03 obtiveram as maiores médias quanto à incidência 
de sigatoka-amarela (doença mais importante da região), na colheita. Este resultado indica que estes genótipos apresentam maior retenção de folhas durante seu ciclo de vida (Lima et al., 2005).

Nos ciclos, foi verificado que os híbridos 4279-06, TH03-01, 8987-01 e 8694-20 apresentaram tendência para a estabilização do número de folhas na colheita, no primeiro ciclo, e o '1318-01', '130406’ e ‘9179-03’, a partir do segundo (Tabela 3).

Em relação à presença de pólen, não foi verificada diferença estatística nos ciclos de avaliação. No entanto, pode-se observar que houve a formação de três grupos entre os híbridos, em que os genótipos 8987-01, 1318-01, 0116-01, 8694-20 e 1304-06 obtiveram as maiores médias, diferindo dos demais (Tabela 3). Vale ressaltar que este caráter é de grande relevância na escolha de genitores masculinos em programas de melhoramento genético da bananeira, uma vez que a ausência de pólen pode interferir na escolha do parental.

Quanto ao período de formação do cacho, além da interação, não se observou diferença estatística entre os três ciclos. Porém, observou-se diferença significativa entre os híbridos em que o '9179-03' foi o mais tardio na colheita. Matos et al. (2001) verificaram que o número de dias da floração à colheita variou de 115,6 (SH32-63) a 142,1 (011601). Segundo Moreira (1999) e Donato (2003), o caráter ciclo do cacho da floração à colheita é muito dependente das condições climáticas, tais como: temperatura, umidade e precipitação.

No número de pencas, não se observou diferença estatística na interação. No entanto, houve a formação de três grupos, segundo o teste de Scott \& Knott. Os híbridos 0116-01 e 1304-06 obtiveram as maiores médias para este caráter, e o diploide 9179-03 obteve média intermediária (Tabela 4), estando de acordo com as observações realizadas por Matos et al. (2001).

Alguns autores (Silva et al., 2006; Flores, 2000) relatam que o caráter número de pencas possui grande interesse para o produtor, assim como para o melhoramento genético da bananeira, uma vez que se constitui na unidade comercial.

O número de frutos, segundo alguns autores (Jaramillo, 1982; Silva et al., 1999), é fundamental na determinação do tamanho e peso do cacho, revelando importância no melhoramento genético, estando diretamente relacionado com o número de pencas. Assim, independentemente do ciclo de avaliação, os híbridos 0116-01, 1304-06 e 9179-03 obtiveram as maiores médias, superando 140 frutos por cacho (Tabela 4).

Quanto à massa dos frutos, mesmo não se observando diferença significativa na interação (Híbridos x Ciclos), verificou-se que, na média dos ciclos, o primeiro apresentou os frutos de maiores massas, quando comparado ao segundo e terceira ciclos (Tabela 4). Em relação à média entre os híbridos, os genótipos 4279-06, TH03-01, 0323-03 e 1318-01 obtiveram os frutos mais pesados, variando entre 35,70 g (1318-01) e 42,50 g (4279-06).

Nota-se que o híbrido TH03-01 apresentou uma das maiores médias para o caráter massa média do fruto, no entanto este genótipo destacou-se por ter poucas folhas na colheita (Tabela 3). Segundo Lessa (2007), este genótipo, por ser híbrido de Terrinha, apresenta frutos maiores, com comprimento em torno de 12,75 cm, sendo esta particularidade, uma possível causa do maior volume de massa no fruto.

Os diploides 4279-06, 0323-03, 1318-01, 0116-01, 1304-06 e 9179-03 apresentaram características agronômicas favoráveis à sua seleção. Essa variabilidade pode ser aproveitada em cruzamento com triploides (variedades comerciais), originando tetraploides ou mesmo triploides, com características agronômicas desejáveis, tendo em vista que o alto vigor do genótipo está associado à poliploidia, já que variedades triploides e tetraploides são bem mais vigorosas que os diploides (Dantas et al., 1999). 
TABELA 1 - Códigos dos híbridos diploides (AA) utilizados no experimento e seus respectivos genótipos parentais.

\begin{tabular}{ll}
\hline $\begin{array}{c}\text { Híbridos } \\
\text { Diploides }\end{array}$ & \\
\hline $4279-06$ & M53 x 2803 (Tuu Gia x Calcutta) \\
TH03-01 & Terrinha x Calcutta \\
8987-01 & 1318-01 (Malaccensis FHIA x Sinwobogi) x 0338-01(Calcutta x Heva) \\
0323-03 & Calcutta (M. acuminata spp. burmannica) x Cultivar sem nome \\
$1318-01$ & Malaccensis FHIA x Sinwobogi \\
0116-01 & Borneo x Guyod \\
8694-20 & 0337-02 (Calcutta x Galeo) x SH32-63 \\
1304-06 & Malaccensis x Madang (Musa acuminata spp. banksii) \\
9179-03 & 0116-01 (Borneo x Guyod)x 2803 (Tuu Gia x Calcutta) \\
\hline
\end{tabular}

${ }^{1}$ Os dois primeiros números referem-se ao genitor feminino, os dois seguintes, ao genitor masculino e os dois últimos, ao número da seleção.

TABELA 2 - Média dos valores obtidos para altura de plantas, diâmetro do pseudocaule e número de folhas na floração em híbridos diploides de bananeira (AA), em Cruz das Almas (BA).

\begin{tabular}{|c|c|c|c|c|c|c|c|c|c|}
\hline \multirow{2}{*}{ Híbridos $^{1}$} & \multicolumn{3}{|c|}{ Altura de plantas (m) } & \multicolumn{3}{|c|}{ Diâmetro do pseudocaule (cm) } & \multicolumn{3}{|c|}{ Número de folhas na floração } \\
\hline & 1 ciclo & 2 ciclo & 3 ciclo & 1 ciclo & 2 ciclo & 3 ciclo & 1 ciclo & 2 ciclo & 3 ciclo \\
\hline 4279-06 & $1,92 \mathrm{cB}$ & $2,75 \mathrm{cA}$ & $2,90 \mathrm{bA}$ & $14,26 \mathrm{aB}$ & $16,45 \mathrm{aA}$ & $17,75 \mathrm{aA}$ & $9,63 \mathrm{bA}$ & 8,93aA & $9,14 \mathrm{aA}$ \\
\hline TH03-01 & $1,83 c B$ & $2,26 \mathrm{dA}$ & $2,34 \mathrm{cA}$ & $12,61 \mathrm{bB}$ & $14,63 \mathrm{bA}$ & $14,47 \mathrm{bA}$ & $12,41 \mathrm{aA}$ & $8,61 \mathrm{aB}$ & $8,22 \mathrm{aB}$ \\
\hline 8987-01 & $1,82 \mathrm{cB}$ & 2,19dA & $2,12 \mathrm{cA}$ & $12,92 \mathrm{bA}$ & $13,55 \mathrm{bA}$ & $11,15 \mathrm{cB}$ & $11,93 a A$ & $8,65 \mathrm{aB}$ & $7,53 \mathrm{aB}$ \\
\hline 0323-03 & $2,23 \mathrm{bB}$ & 2,88bA & $2,20 \mathrm{cB}$ & $14,81 \mathrm{aA}$ & $15,18 \mathrm{bA}$ & $15,00 \mathrm{bA}$ & $10,75 \mathrm{bA}$ & 7,41aB & $8,00 \mathrm{aB}$ \\
\hline 1318-01 & $2,11 b B$ & $2,68 \mathrm{cA}$ & $2,82 \mathrm{bA}$ & $13,55 b B$ & $15,15 \mathrm{bA}$ & $14,75 \mathrm{bAB}$ & $12,04 \mathrm{aA}$ & $8,66 \mathrm{aB}$ & $9,42 \mathrm{aB}$ \\
\hline 0116-01 & 2,16bB & 2,90bA & $3,02 \mathrm{aA}$ & $13,01 \mathrm{bB}$ & $14,87 \mathrm{bA}$ & $15,62 b A$ & 9,96bA & 8,88aAB & $8,00 \mathrm{aB}$ \\
\hline $8694-20$ & 1,63dB & $1,96 \mathrm{eA}$ & $2,02 \mathrm{cA}$ & $13,96 \mathrm{aB}$ & $16,34 \mathrm{a} A$ & $15,38 \mathrm{bAB}$ & $10,00 \mathrm{bA}$ & $8,55 \mathrm{aA}$ & $8,53 a A$ \\
\hline 1304-06 & 2,37aB & $3,12 \mathrm{aA}$ & $3,22 \mathrm{aA}$ & $14,08 \mathrm{aA}$ & $15,00 \mathrm{bA}$ & $15,00 \mathrm{bA}$ & 9,20bA & 7,77aAB & 7,11aB \\
\hline 9179-03 & $1,85 \mathrm{cB}$ & 2,62cA & 2,76bA & $14,02 \mathrm{aA}$ & $14,73 \mathrm{bA}$ & $14,34 \mathrm{bA}$ & $11,28 \mathrm{aA}$ & 8,03aB & $7,25 \mathrm{aB}$ \\
\hline Média & 1,99 & 2,60 & 2,65 & 13,69 & 15,10 & 14,77 & 10,80 & 8,39 & 8,12 \\
\hline CV (\%) & & 4,31 & & & 5,72 & & & 10,42 & \\
\hline
\end{tabular}




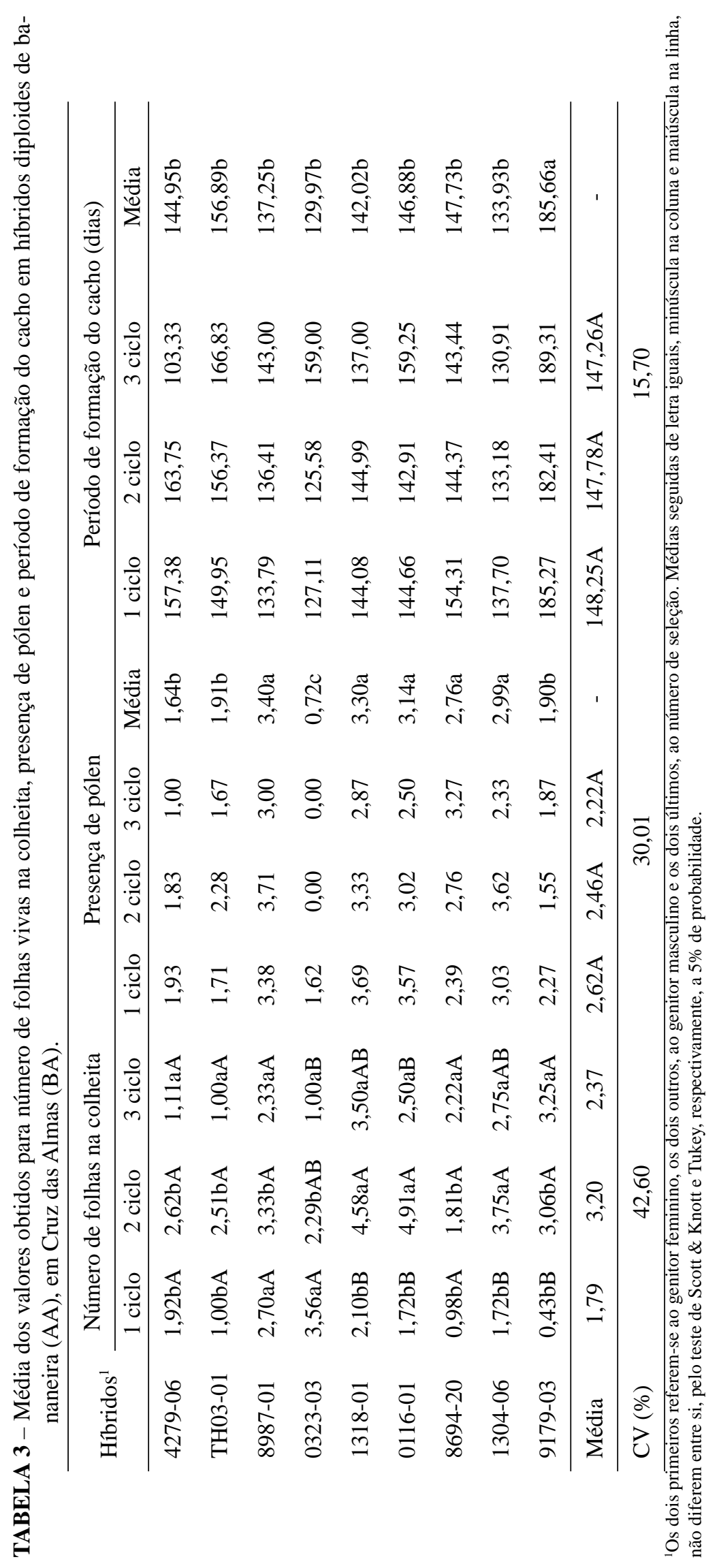

Rev. Bras. Frutic., Jaboticabal - SP, v. 32, n. 1, p.213-221, Março 2010 


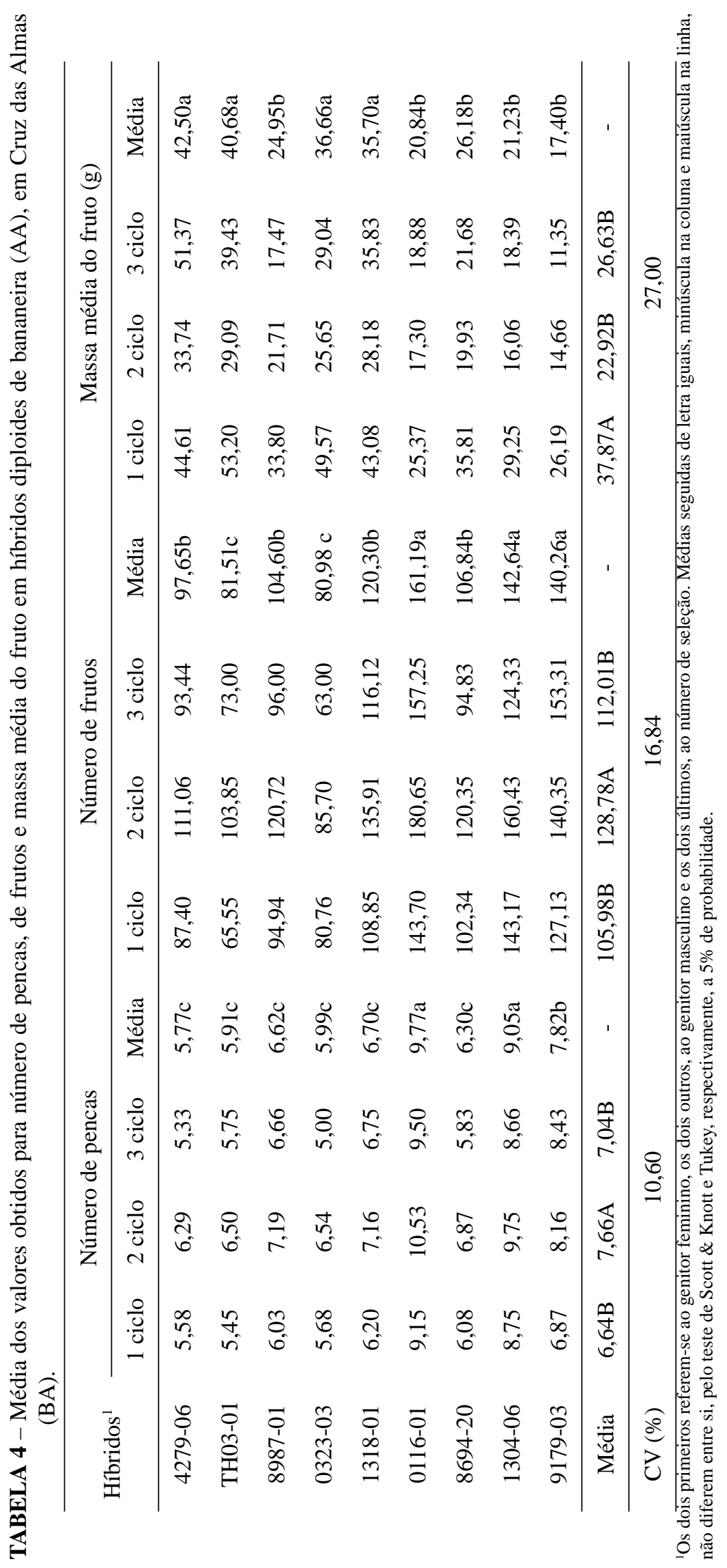




\section{CONCLUSÕES}

Os híbridos 4279-06, 0323-03, 1318-01, 0116-01, 1304-06 e 9179-03 apresentaram características agronômicas favoráveis e podem ser utilizados como genitores em programas de melhoramento genético da bananeira.

\section{AGRADECIMENTOS}

À CAPES, pela concessão da bolsa de mestrado. Ao CNPq, pelo apoio financeiro, e à Embrapa Mandioca e Fruticultura Tropical, pela estrutura de apoio e pelo material vegetal.

\section{REFERÊNCIAS}

AGRIANUAL. Anuário da Agricultura Brasileira. Instituto FNP. São Paulo. 2008. 552p.

AGRITEMPO. Disponível em: http://www.agritempo.gov.br/agroclima/sumario. Acesso em: 03 de jul. 2008.

ALVES, E.J.; OLIVEIRA, M.A. Práticas culturais. In: ALVES, E.J. (Org.). A cultura da Banana: aspectos técnicos, socieconômicos e agroindustriais. 2.ed. rev. Brasília: Embrapa - SPI/ Embrapa-CNPMF, 1999. p. 335 - 352.

AMORIM, E.P.; REIS, R.V.; SANTOS-SEREJO, J.A.; AMORIM, V.B.O.; SILVA, S.O. Variabilidade genética estimada entre diploides de banana por meio de marcadores microssatélites. Pesquisa Agropecuária Brasileira. Brasília, v.43, n.8, p.1045-1052, 2008.

BELALCÁZAR CARVAJAL, S.L. El cultivo del plátano em el trópico. Cali: Imprensora Feriva, 1991. $376 \mathrm{p}$.

BORGES, A.L.; OLIVEIRA, A.M.G.; SOUZA, L.S. Solos, nutrição e adubação. In: ALVES, E.J. (Org.). A cultura da Banana: aspectos técnicos, socieconômicos e agroindustriais. 2.ed. rev. Brasília: Embrapa - SPI/ Embrapa-CNPMF, 1999. p. 197 - 260.

COELHO, E.F.; LEDO, C.A.S.; SILVA, S.O. Produtividade da bananeria 'Prata-Anã' e 'Grande Naine' no terceiro ciclo sob irrigação por microaspersão em tabuleiros costeiros da Bahia. Revista Brasileira de Fruticultura, v. 28, p. 435-438, 2006.
DANTAS, J.L.L.; SHEPHERD, K.; SILVA, S.O.; SOARES FILHO, W.S. Classificação botânica, origem e distribuição geográfica. In: ALVES, E.J. (Org) A cultura da banana: aspectos técnicos, socioeconômicos e agrindustriais. 2.ed. Cruz das Almas: Embrapa CNPMF, p. 27 - 34, 1999.

DONATO, S.L.R. Comportamento de variedades e híbridos de bananeira (Musa spp.), em primeiro ciclo de produção no sudoeste da Bahia, região de Guanambi. 2003, 115f. Dissertação (Mestrado em Ciência e Tecnologia de Sementes). Faculdade de Agronomia “Eliseu Maciel”. Universidade Federal de Pelotas, Pelotas.

DONATO, S.L.R.; SILVA, S.O.; LUCCA FILHO, O.A.; LIMA, M.B.; DOMINGUES, H.; ALVES, J.S. Correlação entre caracteres da planta e do cacho em bananeira (Musa spp). Ciência e Agrotecnologia, Lavras, v. 30, n. 1, p. 21-30, jan/fev., 2006.

DONATO, S.L.R.; SILVA, S.O.; PASSOS, A.R.; LIMA NETO, F.P.; LIMA, M.B. Avaliação de variedades e híbridos de bananeira sob irrigação. Revista Brasileira de Fruticultura, v. 25, n. 2, p. 348-351, 2003.

FAO. Food and agriculture organization of the United Nations. Disponível em: www.faostat.fao. org/site/340/default.aspx. Acesso em: $1^{\circ}$ de set. 2008.

FERREIRA, D.F. Análises estatísticas por meio do SISVAR para Windows versão 4.0. In: Reunião anual da região brasileira da sociedade internacional de biometria, 45., São Carlos, 2000. Resumos. São Carlos: UFSCAR, 2000. p. 255 - 258.

FLORES, J.C. de O. Avaliação de cultivares e híbridos de bananeira (Musa spp.) em quatro ciclos de produção em Cruz das Almas-BA. 2000. 109f. Dissertação (Mestrado em Fruticultura Tropical). Escola de Agronomia, Universidade Federal da Bahia, Cruz das Almas- BA.

IBGE. Sistema IBGE de Recuperação Automática: SIDRA. Disponível em: <http://www.sidra.ibge.gov. br/bda/agric/default.asp?z=t\&o=11\&i $=\mathrm{P}>$. Acesso em: 30 abr. 2009.

JARAMILLO, R.C. Las principales características morfológicas del fruto de banano, variedade Cavendish Gigante (Musa AAA) em Costa Rica. Upeb-Impretex, 42 p. 1982. 
LESSA, L.S. Avaliação agronômica, seleção simultânea de caracteres múltiplos em híbridos diploides (AA) e desempenho fisiológico de cultivares de bananeira. 2007. 83f. Dissertação (Mestrado em Ciências Agrárias). Centro de Ciências Agrárias, Biológicas e Ambientais, Universidade Federal do Recôncavo da Bahia, Cruz das Almas- BA.

LIMA, M.B.; SILVA, S.O.; JESUS, O.N.; OLIVEIRA, W.S.J.; GARRIDO, M.S.; AZEVEDO, R.L. Avaliação de cultivares de bananeira no Recôncavo Baiano. Ciência e Agrotecnologia, Lavras, v. 29, n. 3, p. 515 - 520, maio/jun., 2005.

MATOS, A.P.; CORDEIRO, Z.J.M.; GUZMÁN, M.; SILVA, S.O.; SANDOVAL, J.A.; VILLALTA. Reação à sigatoka-negra e características de produção do primeiro ciclo de híbridos diploides (AA) melhorados de bananeira. Cruz das Almas: Embrapa Mandioca e Fruticultura Tropical, 2001, 27p. (EMBRAPA CNPMF: Boletim de Pesquisa e Desenvolvimento, 21).

MOREIRA, R.S. Banana, Teoria e Prática de Cultivo. 2.ed. CD-ROM. FUNDAÇÃO CARGILL. São Paulo-SP. 1999. (CD-ROM).

OLIVEIRA, C.A.P.; PEIXOTO, C.P.; SILVA, S.O.; LEDO, C.A.S.; SALOMÃO, L.C.C. Genótipos de bananeira em três ciclos na Zona da Mata Mineira. Pesquisa Agropecuária Brasileira, Brasília, v. 42, n. 2, p. 173 - 181, fev. 2007.

SCOTT, A.J.; KNOTT, M.A.A cluster analysis method for grouping means in analysis of variance. Biometrics, Washington, v. 30, n. 3, p. 507-512, sept. 1974.

SHEPHERD, K.; DANTAS, J.L.L.; ALVES, E. J. Melhoramento genético da bananeira. Informe Agropecuário, Belo Horizonte, v.12 p.11-19, 1986.

SILVA, S.O.; FLORES, J.C.O.; LIMA NETO, F.P. Avaliação de cultivares e híbridos de bananeira em quatro ciclos de produção. Pesquisa Agropecuária Brasileira, Brasília, v. 37, n. 11, p. 1567-1574, 2002a.
SILVA, S.O.; ALVES, E.J.; LIMA, M.B.; SILVEIRA, J.R.S. Bananeira. In: BRUCKNER, C.H. (Org.). Melhoramento de Fruteiras Tropicais. Viçosa-MG, v. 1, p. 101-157, 2002b.

SILVA, S.O.; ALVES, E.J.; SHEPHERD, K.; DANTAS, J.L.L. Cultivares. In: ALVES, E.J. (Org.). A cultura da Banana: aspectos técnicos, socieconômicos e agroindustriais. 2.ed. rev. Brasília: Embrapa - SPI/ Embrapa-CNPMF, p. 85 - 105, 1999.

SILVA, S.O.; MORAIS, L.S.; SANTOS-SEREJO, J.A. Melhoramento genético de bananeira para resistência a doenças. In: ROMÃO, R.L.; RAMOS, S.R.R. (Ed.). Recursos Genéticos Vegetais no Estado da Bahia. Feira de Santana: UEFS, p.4967, 2005.

SILVA, S.O.; PASSOS, A.R.; DONATO, S.L.R.; SALOMÃO, L.C.C.; PEREIRA, L.V.; RODRIGUES, M.G.V.; LIMA NETO, F.P.; LIMA, M.B. Avaliação de genótipos de bananeira em diferentes ambientes. Ciência e Agrotecnologia, Lavras, v. 27, n. 4, p. 737-748, 2003.

SILVA, S.O.; PIRES, E.T.; PESTANA, R.K.N.; ALVES, J.S.; SILVEIRA, D.C. Avaliação de clones de banana Cavendish. Ciência e Agrotecnologia, Lavras, v. 30, p. 832-837, 2006.

SILVA, S.O.; ROCHA, S.A.; CREDICO, M.; PASSOS, A.R. Caracterização morfológica e avaliação de cultivares e híbridos de bananeira. Revista Brasileira de Fruticultura, v. 22, p. 156-160, 2000.

SILVA, S.O.; SOUZA JUNIOR, M.T.; ALVES, E.J.; SILVEIRA, J.R.S.; LIMA, M.B. Banana breeding program at Embrapa. Crop Breeding and Applied Biotechnology, v. 1, n. 4, p. 399-436, 2001.

SOTO BALLESTERO, M. Bananos: cultivo y comercialización. 2. ed. San José: Litografía e Imprenta Lil, 1992. 674 p. 